\title{
A RELAÇÃO DO HOMEM COM OS DEMAIS ANIMAIS E O QUE SE CONHECE DELES A PARTIR DA ETOLOGIA E DA CIÊNCIA DO BEM ESTAR ANIMAL
}

\author{
THE RELATIONSHIP BETWEEN HUMAN BEING AND ANIMALS AND KNOWLEDGE \\ ABOUT THEM FROM ETHOLOGY AND ANIMAL WELFARE SCIENCE
}

\author{
A. ZUANON ${ }^{1 *}$, C. FONSECA $^{1}$
}

\begin{abstract}
RESUMO
A Ciência do Comportamento Animal - Etologia, a Ciência do Bem Estar Animal, bem como as múltiplas formas de relação do homem com os demais animais se traduzem, na atualidade, em importantes e instigantes discussões que compõem o quadro de debates sobre Bioética. Historicamente, essa relação tem se modificado e novas formas de se abordar o assunto têm surgido como pauta na (re)qualificação da produção e do pensamento científico. Nos finais do século XIX e durante todo o século XX, tivemos importantes e significativas mostras do quanto o intelecto humano, com sua capacidade investigadora, pôde construir ciências. No panorama internacional da experimentação animal e da educação em medicina veterinária ou zootécnica, correntes reformistas e abolicionistas protagonizaram diversas discussões. Entretanto, um novo paradigma surge e diz respeito a uma nova demanda: a elaboração de um repensar que considere as interfaces existentes entre o Bem Estar Animal, a Etologia, a Bioética e as comissões/comitês de ética no uso de animais. Assim sendo, o presente artigo intenciona, através de uma abordagem de cunho qualitativo e reflexivo, elucidar os contornos que a relação entre homens e os demais animais adquire, caracterizando, para tanto, as cinco liberdades que contribuem para o Bem Estar Animal no cenário da experimentação animal, do ensino e da pesquisa de modo que se pretenda contribuir, também, para o pensamento e desenvolvimento científico das Ciências Veterinárias e Zootécnicas.
\end{abstract}

PALAVRAS-CHAVE: Bioética. Educação veterinária. Experimentação animal.

\section{SUMMARY}

The Animal Behavior Science or Ethology, the Science of Animal Welfare as well as the multiple ways to relationships between human being and animals are translated, nowadays, in important and interesting discussions which compound the debate about Bioethics. Historically, that relationship has been modified and new ways to approach the matter has arisen as question in the new qualification of production of scientific thought. In the end of 19th 20th centuries, it was found out important and meaning results about how human beings' intellect, with its investigative skills, could construct science. In the international outlook of animal experience and education in veterinary or livestock, reformist currents and abolitionist carried out various discussions. However, a new paradigm arises and it is concerning a new demand: the elaboration to rethink the existent interface between the Animal Welfare, Animal Behavior, Bioethics and ethics committees in the use of animals. Thereby, this paper objects, by qualitative and reflexive approaches, to elucidate how to happens the relationship between human beings and animal, by characterizing the five ways to freedom which contribute to the Animal Welfare in the scenery of animal experiment, learning and research, so that to contribute to thought and scientific development of Veterinary and Zootechnical Sciences.

KEY-WORDS: Animal experimentation. Bioethics. Veterinary education.

\footnotetext{
${ }^{1}$ Universidade Federal de Viçosa-MG. Email.: atimazua@ufv.br
} 


\section{CONTEXTUALIZAÇÃO DOS DISTINTOS CAMPOS DA CIÊNCIA}

A Ciência do Comportamento Animal (Etologia), a Ciência do Bem Estar Animal, bem como as múltiplas formas de relação do homem com os demais animais se traduzem, na atualidade, em importantes e instigantes discussões que compõem o quadro de debates sobre Bioética. Historicamente, essa relação tem se modificado e novas formas de se abordar o assunto têm surgido como pauta na (re)qualificação da produção e do pensamento científico. Nesse sentido, partindo da perspectiva de que a bioética hoje representa a combinação da biologia com conhecimentos humanísticos diversos, por acreditar-se que essa se constitui como ciência multidisciplinar e que estabelece parâmetros para garantir uma relação digna e aceitável entre os homens e os outros animais, busca-se destacar, neste artigo, o lugar ou espaço atual para o re-significado dessas questões nas instituições de ensino e de pesquisa.

Dessa forma, este texto intenciona, através de uma abordagem de cunho qualitativo e reflexivo, elucidar os contornos que a relação entre homens e os demais animais adquire, caracterizando, para tanto, as cinco liberdades (livres de fome e sede; livres de desconfortos; livres de dor, ferimentos e doenças; livres para expressar comportamentos fisiologicamente naturais e; livres de medos e angústias) que contribuem para o Bem Estar Animal no cenário da experimentação animal, do ensino e da pesquisa, de modo que se pretenda contribuir, também, para o pensamento e desenvolvimento científico das Ciências Veterinárias e Zootécnicas.

Nos finais do século XIX e durante todo o século XX, tivemos importantes e significativas mostras do quanto o intelecto humano, com sua capacidade investigadora, pôde construir ciências. No panorama internacional da experimentação animal e da educação em medicina veterinária ou zootecnia, correntes reformistas e abolicionistas protagonizaram diversas discussões. Entretanto, um novo paradigma surge e diz respeito a uma nova demanda: a elaboração de um repensar que considere as interfaces existentes entre o Bem Estar Animal, o Comportamento Animal (Etologia) e a Bioética. Nesse contexto, emerge como desafio, uma abordagem de cunho teórico-filosófica que busca cercear o que se conhece a respeito da relação entre homens e demais animais a partir da Etologia e da Ciência do Bem Estar Animal.

Desde os tempos mais remotos, a familiarização com os animais foi essencial para que o homem obtivesse recursos alimentares para sua sobrevivência. Para o homem, conhecer os hábitos de alguns animais significava saber os momentos e os locais certos para pescar e/ou caçar, bem como se defender dos predadores. As estratégias de caça e de pesca dependiam do tamanho e/ou de como as presas se comportavam. No alvorecer de nossa civilização, aproximadamente há 12 mil anos, a humanidade passou a dominar técnicas elaboradas para obtenção das fontes de alimentos e iniciou o processo de domesticação de plantas e de animais, por meio da agricultura e da pecuária (AMABIS e MARTHO, 2005).

Historicamente, há relatos que apontam o período de 1500 a 1800 como um tempo em que se predominou uma visão antropocêntrica na sociedade, no qual se interpretava o mundo como idealizado apenas para os humanos, ao passo que, os não humanos, ou seja, as demais espécies eram tidos apenas como algo de desejo e consumo, caracterizados por diferentes necessidades, tais como trabalho, alimento, companhia, animais de sacrifícios, entre outras formas de servidão. Além disso, vale salientar que os animais desempenham papéis importantes na formação cultural dos povos de todo o mundo, sejam como elementos de cultuação religiosa; como adornos funerários em rituais mortuários na forma de oferendas junto ao corpo dos mortos; elementos para efetuar cálculos matemáticos desde a pré-história; parceiros de trabalho; ou ainda, como animais de companhia (SOUZA, 1988; POLITIS, 1989; RONECKER, 1997; THOMAZ, 2010; CASTELAO, 2011; WALTARI, 2011; SZUCS et al, 2012).

Ainda remetendo à historicidade, neste contexto, há relatos de que após a introdução da carruagem sem cavalos, por volta de 1900, o foco da sociedade humana começou a mudar no que se refere à proximidade do homem com os outros animais. Os cavalos deixaram de ter destaque social em detrimento aos pequenos animais como cães e gatos. A partir disso, estes se tornaram mais prevalentes como animais de estimação. Porém, os animais que estavam a serviço do homem desde os tempos remotos, como o cavalo e o burro, ambos utilizados para suprir a força motriz dos bondes, eram, de certo modo, ainda protegidos. Considerando o fato de os bondes moverem-se sobre trilhos, entendia-se, naquela época, que tal procedimento poupava o esforço despendido pelo animal. Portanto, pode-se dizer que tal realidade já remetia tanto a traços de cuidados como a traços de progresso industrial (HARRISON, 1964).

Entre 1950 e 1960, a formulação da dieta enlatada e a invenção da maca para gatos foram introduzidas no mercado, contribuindo assim para o aumento significativo desses animais, que ganharam visível popularidade. A sociedade mudou o foco dos abrigos de outros animais para a adoção de cães e gatos como animais de estimação. Desta realidade, pela primeira vez, articulou-se o licenciamento para adoção de cães, formulando, para tanto, uma lei aplicável no sentido de transferir a responsabilidade para os proprietários. Além disso, a sociedade propôs "educá-los" sobre a importância da técnica da esterilização nestes animais adultos, argumentando que tal estratégia clínica evita o aumento acelerado e indesejado da população de pequenos animais. Tal iniciativa reduz, significativamente, o número de animais resgatados a cada ano, o que demanda tempo, recurso humano e financeiro.

Nessa perspectiva, busca-se retratar pelo breve resgate histórico, ainda que de forma incipiente e pontual, a proximidade e a interdependência dos humanos e não humanos, exprimindo um processo de transição da relação de dependência para a de companhia. 
Delineando o foco deste artigo, há ainda outro tipo de relação que o ser humano estabelece com os demais seres vivos, que advém da prática da experimentação animal. Sabe-se que neste viés a utilização de animais de laboratório representa um dos dilemas mais polêmicos no debate bioético. Nessa relação, cabe salientar que o "dramatipo" do animal em questão - caráter genotípico e fenotípico afinado com parâmetros estabelecidos e exigidos pelos comitês nacionais e internacionais de ética e bem estar animal, aliado ao adequado projeto de pesquisa, são pré-requisitos essenciais para a significativa redução do número de animais na experimentação. Tendo em vista essa prerrogativa, é possível alcançar resultados com elevado grau de acuidade, reprodutibilidade e precisão nos resultados. Dentre tais parâmetros é possível destacar seleção criteriosa e bem fundamentada do modelo experimental; padronização genética; padronização sanitária do modelo biológico selecionado; padronização do ambiente, transporte e aclimatação; influência do enriquecimento ambiental como exemplo, o provimento de dispositivos de ventilação nas instalações para bovinos; treinamentos de técnicos em experimentação animal; gestão da informação; biossegurança; dieta (DAMY et al, 2010). Para tanto, interessa aqui compreender o sujeito animal por meio de metodologia científica, procurando, para isso, descrever e caracterizar fenômenos biológicos por intermédio de procedimentos dedutivos $\mathrm{e}$ experimentais, formalizando teorias que proponham explicar diferentes aspectos da vida animal.

A preocupação com os aspectos comportamentais é antiga, pois no século IV a.C., Aristóteles já havia publicado obras sobre a origem, a reprodução, a anatomia e o movimento dos animais. Cunha (1983), que traz uma abordagem sobre os princípios básicos da Etologia, faz alusão a Descartes, considerado um inspirador inicial da não relação entre corpo e espírito, por conceber o mecanismo natural do reflexo como uma explicação plausível do comportamento animal, inclusive do comportamento humano, em que não houvesse a intervenção da razão (DESCARTES, 1641 apud CUNHA, 1983). Ao separar radicalmente o espírito e o corpo, como duas ordens incomensuráveis de substâncias, o pensador contribuiu para o avanço da ciência do comportamento, dividida em dois ramos - psicológico e biológico - que, frequentemente, ao longo da história, ora se conflitam, ora se aproximam. A psicologia, concentrando seu interesse nos seres humanos passou a estudar o comportamento animal como forma de esclarecer problemas humanos que não poderiam ser estudados diretamente no mesmo (CUNHA, 1983). A evolução dos estudos acerca da compreensão biológica do comportamento, bem como da psicologia comparada, foi inspirada nas obras de Darwin, um expoente na formulação dos princípios da evolução orgânica. Darwin só não foi considerado fundador da Etologia pelo fato de o comportamento animal não deixar fósseis, apenas alguns - caracteres - traços morfológicos dos organismos (CUNHA, 1983). Um dos primeiros pesquisadores que influenciou ambos os ramos foi William James. Em 1890, ele publicou o livro Principles of Psychology, o qual aborda os conceitos de instintos e reflexos. Notou que os instintos não eram fixos, mas variações comportamentais que tendem a se repetir, apresentando média consideravelmente constante (GRIER, 1984).

Durante a maior parte do século XX, a etologia e a psicologia animal se desenvolveram independentemente. Neste sentido, existem várias razões para explicar a tímida comunicação entre os dois campos: $\boldsymbol{a}$ ) a etologia se desenvolveu inicialmente por intermédio de zoólogos na Europa, enquanto a psicologia animal se desenvolveu, em sua maior parte, na América do Norte. $\boldsymbol{b}$ ) os etologistas trabalharam na perspectiva da teoria evolucionária, ao passo que a psicologia, em geral, estava fora de contato com o pensamento evolucionário, ou mesmo em oposição a ele. c) Os etologistas focalizaram o comportamento inato de animais no campo, enquanto os psicólogos estudaram comportamentos aprendidos de poucas espécies nos laboratórios (SHETTLEWORTH, 2001). Desse modo, os etologistas têm se preocupado com questões comportamentais que levam em conta os aspectos funcionais, adaptativos, ambientais e evolutivos, enquanto mecanismos como percepção, aprendizado, entre outros aspectos cognitivos, são tradicionalmente apresentados sob os domínios da psicologia, evidenciando, entre estes dois distintos campos do saber algum diálogo.

Estudiosos do comportamento animal têm testemunhado, nos últimos anos, a emergência de um número de sub-campos com nomenclaturas que prometem uma integração de aspectos psicológicos e biológicos de mecanismos de processamento de informações, aprendizagem e tomadas de decisões pelos animais. Lopes (1998) e Shettleworth (2001) são destaques entre os estudiosos destes sub-campos como a etologia cognitiva de Ristau, 1991; a ecologia cognitiva; a psicologia evolucionária e a cognição comparativa. O desenvolvimento da ecologia comportamental, da etologia e da cognição comparativa nos últimos anos tem contribuído para enriquecer o elenco de mecanismos cognitivos e problemas funcionais, destacados por Shettleworth (2001). Hoje, sabe-se que as concepções das pessoas acerca do comportamento e das funções cognitivas dos animais não humanos tornaram-se um tema relevante para a compreensão do relacionamento entre outros animais e humanos, com implicações éticas e epistemológicas. Diante destes pressupostos fica evidente a urgência de compreender e validar múltiplos elementos como: $a$ ) os mecanismos que determinam os padrões de comportamento natural dos animais; $b$ ) os elementos que determinam seu grau de bem estar, que juntos lhes conferem valor adaptativo para sobrevivência; c) os programas de preservação; $d$ ) as pesquisas em produção animal; $e$ ) a criação de animais em cativeiro (zoológicos, biotérios); $f$ ) a melhoria na relação médico veterinário paciente e, sobretudo; $g$ ) a adequada e respeitosa utilização dos animais na experimentação animal. Isto posto, acreditamos que a produção do conhecimento científico poderá ser desenvolvida, dentro do âmbito da sustentabilidade, um termo que, na interface com o Bem Estar Animal ganha, quase que unanimemente, aceitação global (FRASER, 2012). Na visão de Feijó et al 2010, pesquisadoras e defensoras dos animais não humanos, é 
possível verificar que a corrente que predomina hoje na esfera da pesquisa é a reformista, ou corrente do bem estar animal, ou ainda welfarista, em detrimento da abolicionista que já desponta no cenário global (protestos), mas ainda com uma tímida aceitação. Entretanto, admitindo que toda e qualquer corrente de pensamento situa, floresce e declina na perspectiva histórico-social, com a corrente reformista não será diferente, pois esta sustenta reformulações graduais de posicionamento e releituras dos cientistas acerca dos animais. Portanto, esse movimento, ora salutar ora contraditório, implica diretamente na apreciação e revisão das legislações, bem como na requalificação da produção científica em consonância com os preceitos da bioética e do ordenamento jurídico e que, cabalmente a levará a uma futura substituição. A concepção e o reconhecimento, na esfera acadêmica, acerca do bem estar animal ganharam notabilidade desde 1926, a partir da criação da Sociedade University of London Animal Welfare (ULAWS) no Reino Unido. Seu fundador, Major Charles Hume, sustentava que as questões relativas aos animais deveriam ser tratadas no campo da cientificidade levando, porém, em consideração certo grau de sentimentalismo. Nota-se que, a partir desse argumento, o fundador já apresentava uma preocupação em garantir um embasamento científico e ético por parte dos adeptos ao mencionado grupo. Desse modo, aspirava que este apresentasse uma postura formal, mas que garantisse, caso deparasse com um animal em sofrimento, a adoção de meios que minimizassem ao máximo tal sofrimento. São considerações humanitárias que clamavam que esses animais fossem tratados com brandura.

Cumpre lembrar que em 2006 estabeleceram-se os princípios norteadores do bem estar animal pela American Veterinary Medical Association's (AVMA), que nos impôs a responsabilidade no provimento da saúde e do bem estar dos animais. Ainda assim, mesmo reconhecendo que a ciência representa a ferramenta legítima para a busca de soluções de problemas correlatos ao bem estar animal, acadêmicos e não acadêmicos devem ter em mente que a força propulsora por trás desta ciência é de cunho social em torno da vigilância da qualidade de vida experimentada pelos sujeitos animais (DUCAN, 2005).

Portanto, é necessário lembrar novamente que o período de conflito de paradigmas e de ideologias no mundo, tecnologias sofisticadas associadas à tecnociência, são elementos utilizados para explorar novos campos ambientais indissociáveis da participação dos demais animais. Desta maneira, pode-se julgar arbitrário o pensamento que só avalia o humano como único portador de valor intrínseco. Tal pensamento assume uma postura antropocêntrica, alimentando assim um especismo em um universo de seres viventes com necessidades e direitos semelhantes. Cabe aos pesquisadores e estudiosos do assunto, bem como também aos leigos e não especializados, como humanidade, munidos de uma rápida evolução cultural e pensando já em tecnociência e/ou sustentabilidade, respeitarem, no âmbito da bioética, os demais animais como seres viventes, sencientes, também dotados de "alma" (PRADA, 1997). Em suas investigações, a neuroanatomista da Universidade de São Paulo, afirma que o sistema nervoso é considerado uma excelente pista para se chegar à alma dos animais, por meio do qual podemos entender que tal campo da ciência derruba o mito da irracionalidade dos "bichos". Tais animais, todavia são incapazes de proclamar pelos seus direitos. Não se deve esquecer que são partícipes de um mundo que já lhes pertencia muito antes de aqui chegar os homens como pretensiosos senhores de tudo e de todos (MILARÉ \& COIMBRA, 2004; RODRIGUES, 2011). As convenções, os tratados de toda ordem econômica, sociológica e jurídica nos exige um comportamento consciente que nos coloca diante de uma arrogante transcendência humana, que predominou o pensamento científico e popular abordado, inclusive nos livros sagrados. Os autores supracitados conduzem à observação de que ao se pronunciar que os animais são sujeitos desprovidos de direitos, por não serem humanos, acarretaria uma inconsistência do ordenamento jurídico.

A relação do homem com os demais animais, a partir de uma orientação filosófica, na Europa, até a revolução francesa, se consolidou, ou pelo menos, se buscou por uma unificação de conhecimentos nas vertentes religiosa, filosófica e científica. Entretanto, é dever ressaltar que na cultura dos europeus, a distinção clara entre os demais animais e o animal humano válida desde o início até o final do século XVIII, na contemporaneidade já não se sustenta. Com o passar dos tempos, a grande produção e a diversidade de campos de saberes no âmbito da ciência, tal unificação acaba sendo renunciada. Nesse contexto o terreno das Ciências Naturais da modernidade começara a ganhar mérito (THOMAZ, 2010). Assim, nos dias de hoje, caso um pesquisador resolvesse furtar-se à busca da verdade, poder-se-ia pensar que esse estaria rejeitando, por exemplo, inúmeros resultados de pesquisas com aplicabilidade para a sociedade, obtidas a partir das experimentações que envolvem o uso dos demais animais. Destacam-se: testes sanguíneos, sorologia, expressão gênica, radioterapia, entre tantos outros de igual importância. De outro modo, o pesquisador não poderia deixar de reconhecer que tais triunfos da cientificidade advindos da atividade humana tomaram do próprio homem sua posição de domínio no mundo como um todo (PAIXÃO, 2001). Emerge daí uma nova questão: e se não existissem os demais animais, a construção da ciência e da tecnologia avançaria tão aceleradamente e sem indagações acerca da própria coexistência - humanos e eles?

No campo da psicologia tem-se como objeto de estudo a equivalência fundamental entre o homem e o outro animal. Tal campo não se restringe ao homem utilizando, assim, iguais métodos para buscar entender os outros animais. Do mesmo modo que se estuda comparando aspectos anatômicos, fisiológicos e bioquímicos, por exemplo, estudam-se comparações comportamentais que elucidam a respeito da alma humana e a dos demais animais. A psicologia moderna abrange todos os seres vivos, incluindo as plantas, no seu universo de investigação científica. Portanto, já se fala de uma biopsicologia, ou seja, outro ramo do conhecimento que propõe o estudo da alma de todos os seres vivos (GODIM, 2005). Há, porém, uma pequena distância entre esse ramo e a bioética, pois pode-se dizer, pontualmente, que a bioética não se trata de uma descoberta do presente. A partir desse aspecto, é possível recorrer, para fins argumentativos, à figura de 
São Francisco de Assis, a qual exprimia um reconhecimento incondicional a todas as formas de vida com as quais conviveu. Estudiosos das religiões apontam como gesto imoral atos humanos que promovam a destruição de tudo que tem vida, pois não há justificativa para tal conduta. Compartilhando dessa proposição, podemos pensar que todos os seres viventes, incluindo as plantas, têm igualdade de direitos, não pelas mesmas coisas, mas cada um com sua singularidade, naquilo que é um pressuposto imprescindível às suas necessidades vitais para o alcance de suas determinações (PAIXÃO, 2001). Existem, também, aqueles que comungam dos ideários indianos ao valorizar o apelo dos seguidores que invocam o sentimento de compaixão para os demais animais. Somando proteção, direito e compaixão, a reivindicação moral assume um tom incontestável no que diz respeito não fazê-los sofrer desnecessariamente. Dito de outro modo, objeta-se às práticas que conduzem à injustiça e meleficiência para com estes seres. No entanto, é possível observar, com frequência, que a sociedade se oculta diante de interesses de ordem maior, o que contribui para a adulteração dos conceitos e o significado amplo de proteção animal. Usualmente os animais domésticos são sacrificados em abatedouros e os silvestres, para nós, muitas das vezes, inofensivos, tornam-se alvo de caçadores, como atividade de lazer e/ou mercadológica. Tal conceito acaba tendo um limite do ponto de vista utilitário: as determinações legais para minimizar tais ocorrências estão longe de serem eficazes em muitas culturas, porém há progressos. É preciso respeitar todo ser vivo essencialmente como um fim em si mesmo e tratá-lo, se possível, como tal. No entanto, vale mencionar que o fato de um espécime não realizar um determinado comportamento típico do grupo, não indica necessariamente privação ou estado de sofrimento (FERREIRA, 2012). As implicações decorrentes da não execução de um mecanismo fisiológico comportamental natural também podem ser variáveis. Ainda assim, também se pode admitir que, o ato da privação elicia um tipo de sofrimento se um determinado espécime for cerceado ou frustrado de exprimir um comportamento importante do ponto de vista fisiológico ao experimentar intensas e prolongadas sensações desagradáveis. Um exemplo: quando um animal é exposto a uma situação experimental na qual ele deixa de ter acesso a um alimento "conhecido e atrativo" para ingerir outro de natureza desconhecida e aparentemente nociva. Neste caso, a imposição do comportamento esperado, para obter informações durante o estudo do mecanismo molecular, da expressão gênica e/ou da funcionalidade das células dos corpúsculos gustativos no animal em questão, implica desconforto. O mecanismo fisiológico da "recusa" desencadeado pelos quimiorreceptores externos como os de olfação e gustação, que são fundamentais para a sobrevivência dos organismos, uma vez que, estes interagem constantemente com o ambiente para a obtenção de informações e tomadas de decisões, nos leva a crer que possivelmente uma manobra de comportamento caracteriza uma tipologia de sofrimento (BROOM \& MOLENTO, 2004). Por outro lado, já foi possível demonstrar que frangos de corte, por exemplo, são capazes de se auto-administrar ingerindo droga com potencial analgésico quando dado a eles a oportunidade de escolher entre duas dietas com cores diferentes sendo a uma delas adicionado um determinado analgésico. Os indivíduos que apresentavam problemas nas patas ingeriram mais alimentos com analgésico quando comparados com os que não tinham problemas. Tal ocorrência observada indica que eles certamente sentem dor e que, havendo chance de superá-la tomarão decisões no sentido de minimizar o sofrimento (DANBURY, et al, 2000). Nesse sentido, é possível caminhar para o raciocínio de que os contextualizadores da abordagem aqui explicitada corroboram a idéia de que um laboratório, um biotério, um abatedouro, uma estação experimental, dentre tantos outros lugares de "bichos" e humanos não podem ser melhores do que as pessoas que também o compõem. De qualquer modo é sabido que a proteção dos animais, numa escala bastante diversificada, ganha cada vez mais espaço e mais adeptos. Portanto, atos imorais versus o exercício da reflexão e mudança de postura têm caminhado juntos, o que nos conduz a pensar que se trata de um avanço nas ciências e nas culturas do nosso povo.

\section{MECANISMOS QUE CONTRIBUEM PARA A MANUTENÇÃO DO BEM ESTAR ANIMAL NO VIÉS DA EXPERIMENTAÇÃO ANIMAL E DO ASPECTO JURÍDICO}

Mais que um campo temático de pesquisa ou áreas multidisciplinares do conhecimento, a Etologia, a ciência do bem estar animal e o biodireito permeiam o terreno da experimentação animal. A primeira, como ciência de nível biológico e operatório, decompõe o comportamento do animal em variáveis, para operacionalmente, constituir um experimento. Mostra como se estrutura e quais os processos que estão envolvidos a partir do exame e/ou tratamento, do concreto singular. Posteriormente, esse processo compara os resultados obtidos com outros comportamentos e tira suas conclusões (MOZER, 1987). A segunda volta-se para o conhecimento e a satisfação das necessidades básicas dos animais, enquanto que a terceira se constitui um ramo que trata da teoria, da legislação e da jurisprudência relativa às normas reguladoras no âmbito do avanço da biologia, da biotecnologia, da medicina humana e veterinária (HIRONAKA, 2003). Nesta perspectiva emerge a seguinte questão: tudo o que é biotecnologicamente possível pode ser também, moral e juridicamente aceito?

É nesse contexto que se pode destacar a importância dos Comitês/Comissões de Ética na vertente da Experimentação Animal. Trata-se de um colegiado interdisciplinar e independente, com munus público, que obrigatoriamente deve existir nas instituições que realizam pesquisas envolvendo os demais animais. Tais órgãos visam defender os direitos dos animais e, ao mesmo tempo, contribuir para o desenvolvimento da pesquisa dentro de padrões éticos (FEIJÓ, 2004).

Neste sentido, todo projeto de pesquisa seja qual for a área de conhecimento, o tipo de curso (tecnológico, graduação, especialização, mestrado, etc.), o perfil do pesquisador (por ex., alunos e/ou 
professores), ou a natureza acadêmica do trabalho (trabalho de conclusão de curso - TCC, artigo científico, monografia, dissertação, tese, dentre outros), deve ser submetido à apreciação de um Comitê/Comissão de Ética no Uso de Animais (CEUA), junto ao Conselho Nacional de Controle de Experimentação Animal (CONCEA), em conformidade com a Lei $\mathrm{N}^{\mathrm{o}} 11.794$ aprovada em 08 de outubro de 2008 e regulamentada pelo Decreto $\mathrm{N}^{\mathrm{o}} 6.899$ de 15 de julho de 2009. A finalidade dessa sistematização do pensamento jurídico foi a de provocar um afastamento das concepções individuais, privativas, arraigadas nas proposições legais anteriores, oferecendo na contemporaneidade um lugar de destaque às relações coletivas, multidisciplinares, que contribuíram para o aumento da preocupação a respeito da experimentação animal. Nessa ordem de ideias, tal ordenamento jurídico deu origem a interesses difusos criando, assim, um espaço fecundo na comunidade científica para o surgimento das interfaces entre o biodireito, a etologia, o bem estar animal e a bioética. É importante saber que a condição sine qua non para que um Projeto de Pesquisa possa ser apreciado por uma CEUA é que o mesmo seja submetido à comissão pelo sujeito pesquisador antes mesmo de ser iniciado. Isso possibilita garantir que o projeto de pesquisa não venha causar prejuízo futuramente aos animais "sujeitos" participantes diretos do experimento. É nesse ponto que se pode referir ao bem estar animal por se considerar que procede, ao pesquisador, alegar desconhecer as normas vigentes no país e iniciar uma pesquisa sem o prévio parecer favorável de um CEUA. Caso contrário, a aprovação e o amparo financeiro para a adequada execução do projeto não poderão ter êxito, podendo resultar no comprometimento da credibilidade. O pesquisador deve considerar, entre outros fatores, que as publicações mais sérias do país exigem que a pesquisa tenha parecer favorável de um comitê/comissão de ética.

Diante desta preocupação, e conseguinte problemática, os coordenadores de cursos, de programas de pós-graduação, docentes e demais orientadores, junto aos seus orientandos, devem estar atentos às exigências/normas para a submissão de projetos, sempre solicitando aos pesquisadores e/ou alunos que submetam seus trabalhos antes de iniciados e em tempo hábil para tramitação e eventuais ajustes de pendências. $O$ comitê/comissão de ética analisa os aspectos éticos da pesquisa em questão, considerando suas relações com a qualidade dos aspectos científicos e metodológicos no que tange ao animal. A análise de um projeto de pesquisa não ocorre estritamente segundo aspectos metodológicos, mas leva em consideração que a metodologia empregada, bem como se o detalhamento de informações correlatas contribui para a relevância da pesquisa respeitando os princípios bioéticos e legais vigentes.

\section{AS CINCO LIBERDADES DO BEM ESTAR ANIMAL E SUAS IMPLICAÇÕES NA EXPERIMENTAÇÃO ANIMAL}

Os defensores do bem-estar animal acreditam que cada criatura é dotada de valor intrínseco merecendo, portanto, ser respeitada e protegida (LEVAI, 2004 \&
RAMOS, 2008). Os animais apresentam necessidades fisiológicas e instintivas, biologicamente determinadas pelo seu perfil genético e associadas ao ambiente. Também são sensíveis à dor, ao sofrimento e aos maus tratos. Em função disso, estudiosos deste campo de conhecimento acreditam que os animais possuem o direito de viver livres de sofrimentos advindos da intervenção humana que, em muitos casos, podem ser mesmo evitada. Porém, bem-estar não diz respeito apenas à ausência de crueldade ou de "sofrimento desnecessário", no que tange à experimentação animal, trata-se de algo mais complexo, definido como um universo de conceitos que abrange: estados naturais, mentais e físicos; as cinco liberdades e ainda necessidades e senciência - capacidade de apresentar uma gama de sentimentos (DUCAN, 2005 \& DAWKINS, 2008). Sabe-se que progresso tem sido notado nos campos da ciência que primam pelo entendimento dos sistemas de comunicação de muitas espécies, o que busca elucidar e abrir novos sub-campos para a abordagem dos sentimentos e da subjetividade dos demais animais. Nesse sentido, o Conselho do Bem-Estar, relativo aos Animais de Produção do Reino Unido, Farm Animal Welfare Council - FAWC, formulou questões pertinentes, baseadas no estudo da etologia - Ciência que estuda o comportamento dos animais - e na Ciência do Bem Estar Animal, a fim de propor, de forma sucinta e de fácil compressão pelo público, as cinco liberdades do bem estar animal. Estas se apresentam inseridas numa abordagem mais ampla e consensual, isto é, sustentada por três eixos centrais para o conceito de bem estar animal representados pela esfera física, comportamental e a esfera psicológica, tendo em vista os preceitos conceituais inseridos nas áreas correlatas supracitadas. Tal proposta auxilia na quantificação, com certa precisão, do grau de bem estar de um determinado animal como ponderam a Sociedade Mundial Protetora dos Animais (WSPA) e a Organização Mundial da Saúde Animal (OIE). As cinco liberdades destinam-se, sobretudo, a aliviar o sofrimento e não a eliminar completamente o estresse do animal, o que caracteriza desse modo boas maneiras de criação. A popularidade destas cinco proposições vem sendo adaptadas e modernizadas nos distintos formatos no sentido de auxiliar o público, os legisladores, os criadores, bem como os docentes pesquisadores a entender como cuidar melhor dos animais (WSPA).

Atualmente, se pode considerar que os animais devem ser satisfatoriamente contemplados nos seguintes aspectos: livres de fome e sede, ou seja, com pronto acesso à água fresca e a uma dieta que os mantenha saudáveis e vigorosos; livres de desconfortos e vivendo em um ambiente apropriado que inclua abrigo e uma área confortável para descanso; livres de dor, ferimentos $e$ doenças por meio de prevenção ou de rápido diagnóstico, seguido de tratamento imediato; livres para expressar comportamentos fisiologicamente normais, uma vez que lhes sejam proporcionados espaços suficientes, condições de acondicionamento apropriado bem como a companhia de outros animais da mesma espécie; livres de medos e angústias e com a garantia de adequada condições de tratamentos que evitem sofrimentos de ordem psicológica. Tais aspectos elencados constam numa lista que ajuda reconhecer a ocorrência de eventos adversos que comprometem o 
bem-estar animal, conforme o entendimento da FAWC, a exemplo, qualquer situação que cause medo, dor, desconforto, ferimento, doença ou ainda "angústias" comportamentais.

No entanto, a avaliação do bem-estar deve ser realizada de forma completamente separada e anteposta de considerações éticas. Ou seja, uma vez terminada, esta prevê as informações necessárias para que decisões éticas possam ser tomadas sobre uma dada situação (BROOM \& MOLENTO, 2008; SOUZA, 2012). Isto posto, e admitindo que a terminologia da expressão "animal de laboratório ou de experimentação" leva em conta qualquer animal que deixa seu habitat natural, pela ação humana e é, de certo modo, obrigatoriamente conduzido para ser o sujeito da pesquisa e/ou do ensino (ANDERSEN et al, 2004), a questão que pode emergir, a partir de então, é: quais e/ou quantas das cinco liberdades, já citadas anteriormente, estão sendo contempladas ao tomarmos estes sujeitos como nosso pertences? Broom e Molento, 2004 já afirmavam que "os profissionais que trabalham com animais enfrentam hoje três desafios emanando de preocupações com bemestar animal: reconhecer que a evolução social alterou as relações entre o ser humano e os animais, freqüentemente em detrimento dos últimos, e que se deve rever esta situação; manter-se informado sobre as explicações que a ciência vem propondo para determinadas respostas dos animais a alguns problemas que os mesmos enfrentam e; refinar as formas de se medir o grau de bem-estar dos animais para que estas avaliações possam ser utilizadas no sentido de se aprimorar as relações entre seres humanos e animais, até que se atinja um nível considerado apropriado por uma sociedade informada e justa". Nesse sentido, importa-se reunir diferentes disciplinas para criar um balizamento ético sobre os problemas gerados advindos tanto do comportamento humano moderno bem como da ciência. Pesquisas que utilizam animais são historicamente legitimadas pela sociedade decorrente do status do cientista frente ao lócus social a que ele ocupa. No entanto, nem por isso justifica-se isentarmos da discutibilidade acerca desta prática nas instâncias decisórias de poder. É neste sentido que discussões éticas e bioéticas representam pautas emergenciais em qualquer "aparelho" de governo democrático, inclusive nas instituições de ensino (MAGALHÃES \& DARO, 2008). Em debates onde se discute os rumos da pesquisa e da pós-graduação nas instituições públicas propõe-se mobilizar o público sobre os rumos a tomar, enfatizando alianças acadêmicas entre nossos governantes e gestores institucionais de outros países com vistas a reunir, cada vez mais, esforços e financiamentos ambiciosos, o que supõe estimular nossa inovação tecnológica. Nesse sentido, a internacionalização da pesquisa e a busca de oportunidades de cooperação assumem um tom de que a ciência caminha em sentido de progresso, detentora de um valor intrínseco, neutra e naturalmente superior às quaisquer outras formas do conhecer. Há quem discorde dessa proposição ao entender que a ciência representa um tipo de conhecimento que coexiste com tantos outros.

Mizubuti (2012) argumenta que o Brasil ocupa a $15^{\mathrm{a}}$ posição no ranking da produção científica mundial e responde por mais da metade da produção latino- americana. Entretanto, na sua visão, os índices de impacto das pesquisas brasileiras ainda são considerados baixos, o que demonstra necessidade de busca por melhorias através de mecanismos de formação de redes de pesquisa nas quais se produz e publicam mais artigos de impacto internacional, além de estimular a inovação, bem como o registro de patentes. Anseia-se nesse núcleo por uma instituição de "classe mundial". O fato é, desconhecemos quais, como e quantas espécies são utilizadas e em que condições de tratamento se apresentam para serem submetidas a determinados procedimentos experimentais (ROESLER, 2010). A partir destas questões emergem as seguintes dúvidas: qual é o índice (\%) da pesquisa nacional que envolve diretamente a utilização de animais, tanto daqueles advindos de modelos produzidos em laboratórios, quanto de campo (cadeia produtiva, silvestres, domesticados)? Essas pesquisas têm levado em conta os preceitos da ciência do bem estar animal? Em quais áreas do saber tais pesquisas ocorrem? Qual a porcentagem de utilização desses animais para cada área do saber? Quais grupos de animais são mais utilizados? Como tem sido feita a descrição legal acerca da procedência destes distintos sujeitos utilizados nas atividades didático-científicas? Existem efetivos e eficientes mecanismos de controle nisso? Se sim, como se dá? As políticas editoriais e de financiamento participam diretamente deste mecanismo de controle? Se sim, como? Já existem em todas as Instituições Federais de Ensino Superior e em Centros de Pesquisa órgãos com autonomia institucional para cuidar especificamente disso? Se isso ocorre por meio de Comitês/Comissões, existe recurso humano qualificado e suficiente para tratar disso? Não há sobrecarga de tarefas? O que mais fragilizaria a eficiência desse processo? Há divulgação ampla desse controle? Se sim, por quais modos de veiculação esta ocorre? Entende-se que todas essas perguntas suscitadas devem ser consideradas e respondidas - banco de dados - no âmbito de cada instituição brasileira oferecendo à sociedade um retrato do cenário brasileiro. Assim, possibilitaria criar sistematicamente eventos regulares de grande abrangência, a fim de debater, com os pares envolvidos, essa pauta emergente que é o modo de produção científica e de educação superior quando se utiliza animais. Ou seja, cabe aos acadêmicos não se deixarem ser tomados por uma indústria de experimentação, que procede desde o provimento de um hidratante até a um teste de equipamentos bélicos, e não dar lugar ao silencio imposto sobre pessoas que nem podem opinar, ainda que tenham dentro de si o espírito da compaixão pelos outros viventes. Ou seja, refere-se àquelas não cônscias das implicações éticas e tão pouco conhecedoras das leis que trata do respeito aos animais (MAGALHÃES \& DARO, 2008).

\section{CONCLUSÕES ARTICULADAS}

Finalizando esta abordagem teórica de cunho reflexivo, sustentar no Artigo 207 da Constituição Federativa Brasileira que dispõe: "as universidades gozam de autonomia didático-científica, administrativa e de gestão financeira e patrimonial, e obedecerão ao 
princípio de indissociabilidade entre o ensino a pesquisa e a extensão" não significa estar legalmente resguardada para assumir gestos de negligência de controle por parte da sociedade e do estado. Assim, fica a seguinte proposta para reflexão: as Comissões/Comitês de Ética no Uso de Animais fariam o papel da sociedade e do estado no controle dessa prática, tendo em vista que estes não extrapolam os espaços acadêmicos, ou, melhor dizendo, que eles não servem exatamente aos interesses de quem os instituem? Se assim for, a autonomia universitária não poderia garantir soberania das atividades didático-científicas sobre os preceitos constitucionais. No entanto, até onde, efetivamente, as Comissões/Comitês já se encontram aparelhadas para desempenharem seu papel e corresponder aos anseios da sociedade? Trata-se de questões que se salientam na atualidade, e que compõem o quadro das novas demandas ressurgentes do campo da experimentação animal, do ensino e da pesquisa na Bioética, que se circunscreve, de igual modo, nas Ciências Veterinárias e Zootécnicas que, cotidianamente lidam com os animais.

\section{REFERÊNCIAS}

AMABIS, J. M.; MARTHO, G. R. Biologia das populações: genética, evolução biológica, ecologia. São Paulo: Moderna, 2005, 438p.

ANDERSEN, M. L.; D’ALMEIDA, V.; KO, G.M.; KAWAKAMI, R.; MARTINS, P. J. F.; MAGAlHÃES, L. E.; TUFIK,S. Princípios Éticos e Práticos do Uso de Animais de Experimentação. São Paulo: UNIFESP, 2004, 167p.

BRASIL, Constituição da República Federativa do Brasil [1988]. Capítulo III da Educação, da Cultura e do Desporto. Seção da Educação. Artigo 207. Disponível em: <http://www.planalto.gov.br/ccivil_03/constituicao/con stituicao.htm>. Acesso em: 03/08/13.

BROOM, D. M.; MOLENTO, C. F. M. Archives of Veterinary Science, v.9, n.2, p.1-11, 2004.

CASTElaO, C. A vida sem números. Super interessante, edição 296, p.6 -71. 2011.

CUNHA, W. H. A. Introdução ao desenvolvimento histórico e aos princípios básicos da etologia. In: ENCONTRO PAULISTA DE ETOLOGIA, 1983, Jaboticabal, SP. Anais do I Encontro Paulista de Etologia, p.1-33.

DAMY, S. B.; CAMARGO. R. S.; CHAMMAS, R.; FIGUEIREDO, L. F. P. Aspectos fundamentais da experimentação animal: aplicações em cirurgia experimental. Revista Associação Medicina Brasileira, v.56, n.1, p.103-111, 2010.

DANBURY, T. C.; WEEKS, C. A.; CHAMBERS, J. P.; WATERMAN-PEARSON A. E.; KESTIN, S. C. Self-selection of the analgesic drug carprofen by lame broiler chickens. Veterinary Record. v.146. n.11, p.307-311, 2000.
DAWKINS, M., S. The science of animal suffering. Etology, v.114, p.937- 945, 2008.

DUCAN, I. J. D. Science-based assessment of animal welfare: farm animals. Revue Scientifique et Technique (Internacional Office of Epizootics), v.24. n.2, p.483-492, 2005.

FEIJÓ, A. G. S. A função dos Comitês de ética institucionais ao uso de animais na investigação científica e na docência. Bioética, v.12. n.2, p.11-22, 2004.

FEIJÓ, A. G. S.; SANTOS, C. I.; GREY, N. C. [2010]. $\mathrm{O}$ animal não-humano e seu status moral para a ciência e o direito no cenário brasileiro. Bioética Y Derecho. n.19, p.1-7, 2010. Disponível em: <http://www.bioeticayderecho.ub.es>. Acesso em: 09/05/13.

FRASER, D. Compreendendo o Bem - estar Animal: a Ciência no seu contexto cultural. Londrina. PR: Eduel. 2012. 436p.

FERREIRA, S. R. A. A dimensão do sofrimento animal. Revista CFMV, n.55, p.72-74. 2012.

GODIM, J. R. Bioética: um panorama sobre as relações éticas do ser humano com os animais e as plantas. Tradutor de Bio-Ethics: A Review of the Ethical Relationships of Humans to Animals and Plantas. JAHR. F. Kosmos, Gesellschaft der Naturfreunde, Stuttgart. n. 24. 1927. Franckh'sche Verlagshandlung, Stuttgart: 2005.

GRIER, J. W. Biology of animal behavior. St. Louis: Times Mirror: Mosby College Publishing, 1984. 740p. HARRISON, R. Animal machine: the new factory farming industry. London: Vicente Stuart, 1964. $186 \mathrm{p}$.

HIRONAKA, G. M. F. N. [2003]: Bioética e o biodireito: revolução biotecnológica, perplexidade humana e prospectiva jurídica inquietante. Revista Brasileira de Direito da Família, n.16, 2003. Disponível $<$ http://www.answers.com/topic/institute-ofmedicine\#ixzz1zsOOQrzC>. Acesso em 14/04/12.

LEVAI, L. F. Direito dos animais. Campos do Jordão: Mantiqueira, 2004, 159p.

LOPES, C. F. Como falam esses chimpanzés. Globo ciência, n.82, p.20-27, 1998.

MAGALHÃES, V. B.; DARO, V. R. Ciência e Poder: pesquisas com animais e autonomia universitária. In: CONGRESSO BRASILEIRO DE BIOÉTICA E DIREITOS DOS ANIMAIS, 2008, Salvador.

MILARÉ, E.; COIMBRA, J. A. A. Antropocentrismo x ecologismo na ciência jurídica. Revista de direito ambiental, `v.36, p.9-42, 2004. 
MIZUBUTI, E. Os rumos da Pesquisa e da PósGraduação da Universidade Federal de Viçosa. In: SEMINÁRIO DE PESQUISA E PÓS-GRADUAÇÃO, Viçosa. MG, 2012.

MOLENTO, C. F. M. O ensino de Bem Estar Animal no Brasil e no Mundo. Revista do Conselho Federal de Medicina Veterinária, n.44, p.80-81, 2008.

MOZER, A. As bases filosóficas da etologia. Anais de etologia, v.5, p.01-10. 1987.

PAIXÃO, R. L. Experimentação animal: razões e emoções para uma ética. Rio de Janeiro. Fundação Osvaldo Cruz, 2001. 189p. Tese (Doutorado em Saúde Pública) - Escola Nacional de Saúde Pública.

POLITIS, G. Quem matou o megatério? Ciência Hoje, v.9, n.51, p.44-53, 1989.

PRADA, I. L. S. A alma dos animais. São Paulo: Mantiqueira, 1997. 63p.

RAMOS, J. B. Direito dos animais: ética e respeito. [2008]. Disponível em: <http://ambientese.blogspot.com.br/2008_09_01_archi ve.html>. Acesso em 29/01/14.

RISTAU, C. A. Cognitive ethology: the minds of animals. Lawrence Erlbaum Associates, Hilldale, 1991. 332p.

RODRIGUES, D. T. O direito e os animais: uma abordagem ética, filosófica e normativa, Curitiba, PR: Juruá, 2011.245p.

OESLER, R. Ética na Ciência. CONGRESSO DA SOCIEDADE BRASILEIRA DE BIOLOGIA CELULAR, 2010, São Paulo.
RONECKER, J. P. Simbolismo animal: mitos, crenças, lendas, arquétipos, folclore, imaginário. Tradução de Benoni Lemos. São Paulo: Paulus, 1997. 392p.

SHETTLEWORTH, S. J. Animal cognition and animal behaviour. Animal Behaviour, Amsterdam,v.61, n.2, p.277- 86. 2001.

SOUZA, L. M. Feitiços e bruxarias. Ciência Hoje, v.7, n.40, p.30-36, 1988.

SOUZA, M. C. L. Consumo sustentável de carne: um estudo exploratório da reação do consumidor às informações sobre maus-tratos. Revista do Conselho Federal de Medicina Veterinária, n.57, p.71-75, 2012.

SZUCS, E.; GEERS, R.; JEZIERSKI, T.; SOSSIDOU, E. N.; BROOM, D. M. Animal welfare in different human cultures, tradiditions and religious faiths. Australasian Journal the Animal Science, v.25, n.11, p.1499-1506, 2012.

THOMAZ, K. O homem e o mundo natural: mudanças de atitude em relação às plantas e aos animais, 1500 a 1800. São Paulo: Companhia das Letras. 2010, 537p.

WALTARI, M. O egípcio. Curitiba: Juruá, 2011, 245p. WORLD SOCIETY FOR THE PROTECTION ANIMALS (WSPA). Disponível em <http://www.wspa-international.org/> Acesso em $22 / 02 / 14$.

WORLD ORGANISATION FOR ANIMAL HEALTH (OIE). Disponível em:< http://www.oie.int/for-themedia/editorials/detail/article/81st-general-session-ofthe-oie-continuing-mobilisation-of-efforts-to-protectanimals/>. Acesso em 22/02/14. 